\title{
Therapeutic inhibition of galectin-3 improves cardiomyocyte apoptosis and survival during heart failure
}

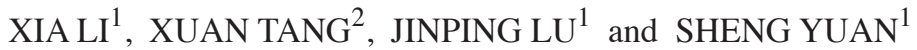 \\ ${ }^{1}$ Department of Geriatrics, Zhongnan Hospital of Wuhan University, Wuhan, Hubei 430071; \\ ${ }^{2}$ Department of Laboratory Medicine, Jingzhou Central Hospital, The Second Clinical Medical College, \\ Yangtze University, Jingzhou, Hubei 434020, P.R. China
}

Received April 27, 2016; Accepted October 24, 2017

DOI: $10.3892 / \mathrm{mmr} .2017 .8323$

\begin{abstract}
Galectin-3 is an important mediator of cardiac fibrosis and heart failure. Cell viability of cardiomyocytes was measured using a CCK-8 assay; flow cytometry was employed for the detection of the cell cycle and cardiomyocytes apoptosis. Reverse transcription-quantitative polymerase chain reaction and western blotting was performed to examine the expression of associated genes and proteins. The present study demonstrated that overexpression of galectin-3 significantly decreased the viability of cardiomyocytes in a time-dependent manner, with simultaneous arrest of the cell cycle and induction of apoptosis. The expression levels of proliferating cell nuclear antigen (PCNA) and B-cell lymphoma 2 (Bcl-2) were decreased and $\mathrm{Bcl}-2$-associated $\mathrm{X}$ protein (Bax) was increased in cardiomyocytes with galectin-3 overexpression. However, inhibition of galectin-3 by intravenous tail vein injection of a galectin-3-targeting short hairpin RNA-expressing vector during hypertension-induced heart failure in Dahl hypertensive rats increased rat survival and body weight. Inhibition of galectin-3 also increased the expression of PCNA and Bcl-2 and reduced the expression of $\mathrm{Bax}$ in the cardiac tissue of hypertensive rats. These results demonstrate the therapeutic potential of targetinggalectin-3 for the treatment of cardiac disease.
\end{abstract}

\section{Introduction}

Chronic and acute stress to the heart results in a pathological remodeling response accompanied by cardiomyocyte hypertrophy, fibrosis, myocyte degeneration and apoptosis, finally contributing to heart failure (HF) (1). HF is a progressive disorder characterized by poor quality of life and poor

Correspondence to: $\mathrm{Dr} \mathrm{Xia} \mathrm{Li}$, Department of Geriatrics, Zhongnan Hospital of Wuhan University, 169 Donghu Road, Wuhan, Hubei 430071, P.R. China

E-mail: lixiallxx@126.com

Key words: heart failure, cardiomyocytes, galectin-3, apoptosis, survival prognosis. In recent years HF has reached endemic proportions in the industrialized world, with 5.7 million patients affected by this disease in the United States (2). Similarly striking data are also observed in Europe and Asia, and the incidence of critical risk factors for HF have also markedly increased $(3,4)$. The prevalence of HF is expected to rise due to the aging population and improved treatment of cardiovascular diseases that precede HF (5). Therefore, it is imperative that novel methods to improve the treatment of $\mathrm{HF}$ are identified.

Cardiac remodeling is an important determinant in the clinical outcome of HF; it is linked to disease progression and poor prognosis (6). Cardiac fibrosis is an important contributor to the pathophysiology of cardiac remodeling caused by hypertension. Galectin-3 is a $\beta$-galactoside-binding lectin that appears to be a mediator of cardiac fibrosis in several experimental studies $(7,8)$. The potential HF-promoting actions of galectin-3 have been described (9), although the precise mechanisms still warrant further investigation. Galectin-3 is produced by macrophages and fibroblasts, but not by cardiomyocytes, in rat and mouse models of progressive cardiac remodeling $(10,11)$. The pro-fibrotic characteristics of galectin-3 have also been demonstrated in models of pathological fibrosis in kidney and liver, suggesting that fibrosis may be a hallmark of cardiac remodeling and HF (12). Although several prognostic studies of patients with HF have indicated the independent predictive value of galectin-3 for cardiovascular outcomes, others have questioned whether galectin-3 is truly independently associated with adverse cardiac events $(13,14)$. The observations provide evidence for the hypothesis that longstanding elevated galectin-3 may not signify disease, but likely represents a unique phenotype at high risk for the development and progression of heart failure.

The mechanism of galectin-3 as a promoter of the development of HF has not been investigated. The present study aimed to explore the mechanism by which galectin-3 may be associated with cardiomyocyte apoptosis and survival during $\mathrm{HF}$.

\section{Materials and methods}

Isolation of cardiomyocytes and cell culture. Isolation of cardiomyocytes and cell culture was performed as previously described (15). In brief, animals were anesthetized by an intraperitoneal injection of chloral hydrate $(300 \mathrm{mg} / \mathrm{kg})$. 
Perfusion with fixatives (4\% paraformaldehyde, $2.5 \%$ glutaraldehyde) was used as the primary method of euthanasia. The heart was excised and perfused using the retrograde Langendorff technique. Subsequently, the perfusion buffer was supplemented with $0.6 \%$ collagenase II and $0.6 \%$ bovine serum albumin (both from Invitrogen; Thermo Fisher Scientific, Inc., Waltham, MA, USA), and the buffer was recirculated for $12-15 \mathrm{~min}$ at $25^{\circ} \mathrm{C}$. The dissociated cells, including the majority of the cardiomyocytes, were filtered through a $200 \mu \mathrm{m}$ mesh. The cardiomyocytes were preplated for $1 \mathrm{~h}$ [2 mM L-glutamine and 10\% FBS in Dulbecco's modified Eagle's medium (DMEM); Invitrogen; Thermo Fisher Scientific, Inc.] at $37^{\circ} \mathrm{C}$ in a humidified atmosphere of $5 \% \mathrm{CO}_{2}$ and $95 \%$ air to enrich the culture, and were subsequently cultured in serum-free DMEM (Invitrogen; Thermo Fisher Scientific, Inc.) for $24 \mathrm{~h}$ at $37^{\circ} \mathrm{C}$ in a humidified atmosphere of $5 \% \mathrm{CO}_{2}$ and $95 \%$ air.

Overexpression and construction of stable cell lines. The galectin-3 coding sequence was purchased from Sangon Biotech Co., Ltd. (Shanghai, China) and the sequence was cloned into the pcDNA3.1(+) vector (Sangon Biotech Co., Ltd.). The primers used were as follows: Galectin-3 forward, 5'-CGGGATCCTTAGATCATGGCGTGGTTAGC-3' and reverse, 5'-CGGGATCCTTAGATCATGGCGTGGTTAGC-3'. The sequences were annealed and digested using EcoRI and $B a m \mathrm{HI}$, and were ligated into the pcDNA3.1(+) vector. An empty pCDNA3.1(+) vector served as the negative control (NC). The pCDNA3.1(+) vector encoding galectin-3 $(1 \mu \mathrm{g})$ was subsequently transfected into the cardiomyocytes using Lipofectamine ${ }^{\circledR} 2000$ (Invitrogen; Thermo Fisher Scientific, Inc.), according to the manufacturer's instructions. All assays were performed $48 \mathrm{~h}$ following transfection.

Cell viability analysis. Following transfection, cardiomyocytes were plated into 96 -well plates at $1 \times 10^{3}$ cells/well in a final volume of $100 \mu \mathrm{l}$, and cultured overnight. Cell viability was determined using a Cell Counting Kit-8 (CCK-8; Dojindo Molecular Technologies, Inc., Kumamoto, Japan) assay, according to the manufacturer's instructions. In brief, at 24, 48 and $72 \mathrm{~h}$ following transfection, $10 \mu \mathrm{l} \mathrm{CCK}-8$ solution was added to each well and incubated for $1 \mathrm{~h}$ at $37^{\circ} \mathrm{C}$ and $5 \% \mathrm{CO}_{2}$. Following incubation, absorbance was measured at $450 \mathrm{~nm}$ using a microplate reader (SM600 Labsystem; Shanghai Utrao Medical Instrument Co., Ltd., Shanghai, China).

Cell cycle and apoptosis analysis. For the cell cycle assay, $3 \times 10^{4}$ transfected cells were collected and fixed in $70 \%$ ethanol at $-20^{\circ} \mathrm{C}$ overnight. The cells were subsequently washed in PBS and resuspended in staining solution containing $20 \mu \mathrm{g} / \mathrm{ml}$ propidium iodide (PI; Sigma-Aldrich; Merck KGaA, Darmstadt, Germany) and $200 \mu \mathrm{g} / \mathrm{ml}$ RNase A. Cell cycle was assessed by flow cytometry, using BD Accuri C6 software version 1.0.264.21 (BD Biosciences, Franklin Lakes, NJ, USA). For the cell apoptosis assay, $3 \times 10^{4}$ transfected cells were collected by trypsinization (Jrdun Biotechnology Co., Ltd., Shanghai, China) and incubated with $195 \mu$ l Annexin V-fluorescein isothiocyanate for $15 \mathrm{~min}$ at $4^{\circ} \mathrm{Cand} 5 \mu \mathrm{PI}$ for $5 \mathrm{~min}$ at $4^{\circ} \mathrm{C}$, prior to analysis using a flow cytometer (BD Biosciences, Franklin Lakes, NJ, USA).
Following this, the results were subsequently analyzed using CellQuest software (version 5.1; BD Biosciences).

Animals and treatment. A total of 18 male Dahl salt-sensitive rats (weight, 200-250 g) purchased from Shanghai SLAC Laboratory Animal Co., Ltd. (Shanghai, China) were fed a high-salt (HS) diet $(8.0 \% \mathrm{NaCl})$ starting at 8 weeks of age, which progresses to a model of congestive HF (16). Rats (6/cage) were housedin an animal facility at $25^{\circ} \mathrm{C}$, with a relative humidity of $60-70 \%$ and received food and water ad libitum. After 1 week on the HS diet, $25 \mu \mathrm{g} / \mathrm{kg}$ lentivirus containing gal-3 short hairpin (sh)RNA sequence (pLKO-shGAL3 cat. TRC0000029305; OpenBiosystems; Thermo Fisher Scientific, Inc.) was intravenously injected via the tail vein (6/goup). The shRNA scramble sequence was used as a transduction control for 3 weeks. After 4 weeks on the HS diet, the rats were sacrificed and weighed. Cardiac tissue samples were collected at the indicated time-points for molecular or histological examination, which were frozen at $-80^{\circ} \mathrm{C}$ and fixed with $4 \%$ paraformaldehyde for $48 \mathrm{~h}$ at $25^{\circ} \mathrm{C}$. The survival time of rats with galectin-3 knockdown treatment was measured during the 4 weeks. The investigation conformed to the Guide for the Care and Use of Laboratory Animals published by the U.S. National Institutes of Health (17). The study was approved by the ethics committee of Zhongnan Hospital of Wuhan University (Wuhan, China).

Reverse transcription-quantitative polymerase chain reaction (RT-qPCR) analysis. For in vitro and in vivo RT-qPCR analyses, RNA was extracted from cardiomyocytes or cardiac tissue with TRIzol (Life Technologies; Thermo Fisher Scientific, Inc.). A total of $1 \mu \mathrm{g}$ RNA was used to generate cDNA using a M-MLV RT Reagent kit according to the manufacturer's instructions (Thermo Fisher Scientific, Inc.). To detect the level of galectin-3, proliferating cell nuclear antigen (PCNA), B-cell lymphoma 2 (Bcl-2) and Bcl-2-associated X protein (Bax), qPCR was performed with a SYBR Green qPCR Master mix (Takara Biotechnology Co., Ltd., Dalian, China) and data collection was conducted using an ABI 7500 (Applied Biosystems; Thermo Fisher Scientific, Inc.). The PCR cycling conditions were as follows: $95^{\circ} \mathrm{C}$ for $10 \mathrm{~min}$, followed by 40 cycles at $95^{\circ} \mathrm{C}$ for $15 \mathrm{sec}$ and $60^{\circ} \mathrm{C}$ for $45 \mathrm{sec}$, and a final extension step of $95^{\circ} \mathrm{C}$ for $15 \mathrm{sec}, 60^{\circ} \mathrm{C}$ for $1 \mathrm{~min}, 95^{\circ} \mathrm{C}$ for $15 \mathrm{sec}$ and $60^{\circ} \mathrm{C}$ for $15 \mathrm{sec}$. GAPDH was used an endogenous control for normalization. The gene expression was calculated using the $2^{-\Delta \Delta \mathrm{Cq}}$ method (18). The primers (Sangon Biotech Co., Ltd.) used were as follows: Galectin-3 forward, 5'-CATTGTGTGTAACACGAAGCA GGAC-3' and reverse, 5'-CTGCAGTAGGTGAGCATCGTT GA-3'; GAPDH forward, 5'-GGAATCCACTGGCGTCTT CA-3' and reverse, 5'-GGTTCACGCCCATCACAAAC-3'; Bcl-2 forward, 5'-CCACCTGTGGTCCATCTGAC-3' and reverse, 5'-CAATCCTCCCCCAGTTCACC-3'; Bax forward, 5'-GTCATCTCGCTCTGGTACGG-3' and reverse, 5'-CAC ACACACAAAGCTGCTCC-3'; PCNA forward, 5'-CCCTGG AGCCCTTGAAGAAG-3' and reverse, 5'-AGATGCACAACT TCTCGGCA-3'.

Western blot analysis. Mouse monoclonal antibodies against galectin-3 (1:1,000; cat. no. sc-374253) and the rabbit polyclonal antibodies against $\operatorname{Bax}(1: 500$; cat. no. sc-493) and 
A

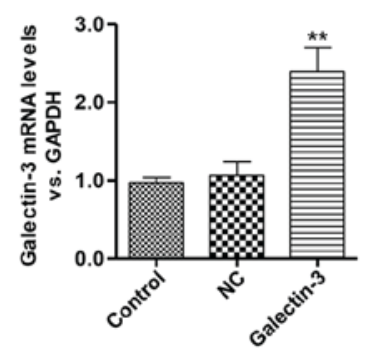

B

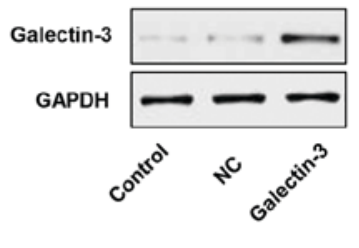

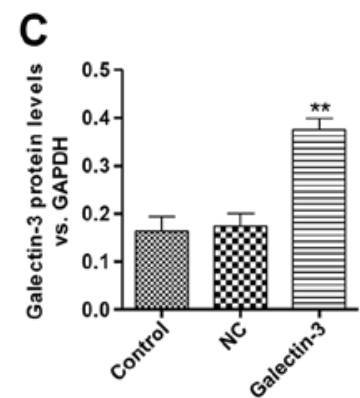

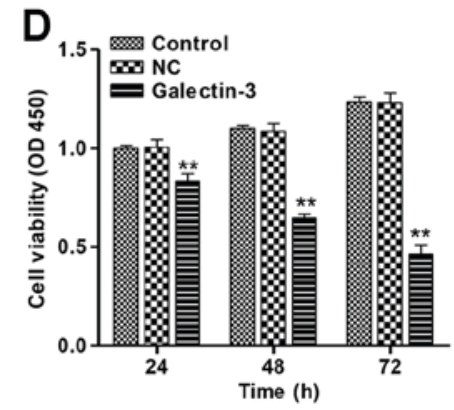

Figure 1. Effects of galectin-3 overexpression on the cell viability of cardiomyocytes. (A) Reverse transcription-quantitative polymerase chain reaction analysis of galectin-3 expression profiles in three treatment groups. (B) Western blot analysis and (C) semi-quantification of galectin-3 expression profiles in three treatment groups. (D) Cell viability of cardiomyocytes with galectin-3 overexpression was measured by Cell Counting Kit- 8 assay. Data are presented as the mean \pm standard deviation $(\mathrm{n}=3) .{ }^{* *} \mathrm{P}<0.01$ vs. NC group. $\mathrm{NC}$, negative control; OD, optical density.

Bcl-2 (1:1,000; cat. no. sc-492) were purchased from Santa Cruz Biotechnology, Inc. (Dallas, TX, USA). Rabbit monoclonal antibodies against PCNA (1:1,000; cat. no. 13110) and GAPDH (1:1,000; cat. no. 5174) were purchased from Cell Signaling Technology, Inc. (Danvers, MA, USA). Horseradish peroxidase-conjugated goat anti-rabbit $(1: 1,000$; cat. no. A0208) and anti-mouse (1:1,000; cat. no. A0216) secondary antibodies were purchased from Beyotime Institute of Biotechnology (Haimen, China). Proteins were detected by western blot analysis as previously described (19). The total cell lysates were extracted using radioimmunoprecipitation buffer (Amyjet Scientific, Inc., Wuhan, China) according to the manufacturer's instructions. The protein concentration was determined using a Bicinchoninic Acid Protein Assay kit (cat. no. PICPI23223; Thermo Fisher Scientific, Inc.). A total of $15 \mu \mathrm{l}$ of proteins were subjected to 10 or $15 \%$ SDS-PAGE, transferred to polyvinylidene fluoride membranes (Sigma-Aldrich; Merck $\mathrm{KGaA}$ ) and blocked in fat-free milk overnight at $4^{\circ} \mathrm{C}$. The membranes were subsequently incubated with primary antibodies for $2 \mathrm{~h}$ at $25^{\circ} \mathrm{C}$ and then with secondary antibodies for $1 \mathrm{~h}$ at $37^{\circ} \mathrm{C}$, and were visualized using an enhanced chemiluminescence kit (EMD Millipore, Billerica, MA, USA) and signals were semi-quantified by densitometry (Quantity One software, version 4.62; Bio-Rad Laboratories, Inc., Hercules, CA, USA).

Statistical analysis. Data were presented as the mean \pm standard deviation with three repeats and were analyzed using GraphPad Prism 5 software (GraphPad Software, Inc., La Jolla, CA, USA). Differences were assessed using a one-way analysis of variance, followed by Tukey's post hoc test. Survival analysis was performed by the Kaplan-Meier method, and subjected to the log rank test. $\mathrm{P}<0.05$ was considered to indicate a statistically significant difference.

\section{Results}

Galectin-3 overexpression inhibits the viability of cardiomyocytes. To investigate the role of galectin-3 in cardiomyocytes, a galectin-3 overexpression vector was constructed; the galectin-3 coding sequence was cloned into a pCDNA3.1(+) vector, and the empty vector was used as NC. At $48 \mathrm{~h}$ after transfection, the expression of galectin-3 was determined using RT-qPCR (Fig. 1A) and western blotting
(Fig. 1B and C). The overexpression vector significantly increased the expression of galectin-3 in cardiomyocytes at the mRNA and protein levels.

To determine the impact of galectin-3 overexpression on the viability of cardiomyocytes, the cell viability of galectin-3-overexpressing cardiomyocytes was analyzed by CCK- 8 assay. Cell viability was significantly reduced in the galectin-3-overexpressing cardiomyocytes compared with the control and NC groups (Fig. 1D). There was no significant difference between the control and NC groups. These data suggest galectin-3 may have a role in the cell viability of cardiomyocytes.

Galectin-3 overexpression induces cell cycle arrest and apoptosis of cardiomyocytes. The potential inhibitory effect of galectin-3 overexpression on cell cycle progression was investigated. As presented in Fig. 2A, overexpression of galectin-3 resulted in a lower number of cells in the $\mathrm{G}_{0}-\mathrm{G}_{1}$ phase $(54.54 \pm 4.18 \%)$ compared with the $\mathrm{NC}$ group $(69.11 \pm 3.17 \%)$. Furthermore, there was a higher number of cells in the $\mathrm{S}(26.94 \pm 1.39 \%)$ and $\mathrm{G}_{2}-\mathrm{M}$ phases $(16.64 \pm 1.52 \%)$, compared with the corresponding NC groups (S phase, $19.59 \pm 2.24 \% ; \mathrm{G}_{2}-\mathrm{M}$ phase, $9.86 \pm 1.46 \%$ ). These data suggest that galectin-3 overexpression may induce cell cycle arrest at $\mathrm{S}$ and $\mathrm{G}_{2}-\mathrm{M}$ phases, which may be associated with reduced cell viability in galectin-3-overexpressing cardiomyocytes.

To assess the effects of galectin-3 overexpression on cell apoptosis, Annexin V/PI staining was performed (Fig. 2B). The ratio of cells undergoing apoptosis was significantly increased to $27.17 \pm 2.32 \%$ in galectin-3-overexpressing cardiomyocytes, compared with the NC group $(4.33 \pm 1.31 \%)$. These results indicate that galectin-3 may promote apoptosis in cardiomyocytes.

Effects of galectin-3 overexpression on PCNA, Bcl-2 and Bax expression in cardiomyocytes. PCNA is a protein that is synthesized in early $\mathrm{G}_{1}$ and $\mathrm{S}$ phases of the cell cycle and functions in cell cycle progression, DNA replication and DNA repair (20). The proteins of the Bcl-2 family perform critical roles in the regulation of apoptosis by functioning as promoters (i.e., Bax) or as inhibitors (i.e., Bcl-2) of cell death progression (21). RT-qPCR and western blot analysis were performed to detect the mRNA and protein expression levels of PCNA, Bcl-2 and Bax. Galectin-3 overexpression resulted in a marked reduction in the levels of PCNA and Bcl-2, with a concomitant increase in the level of Bax compared with the corresponding NC groups (Fig. 3). These 
A

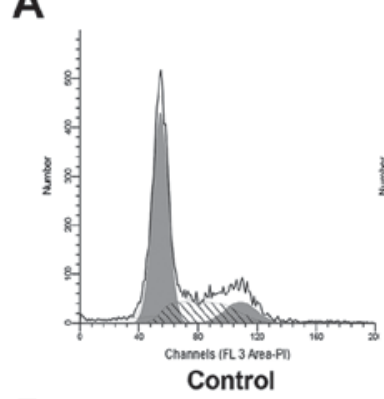

B

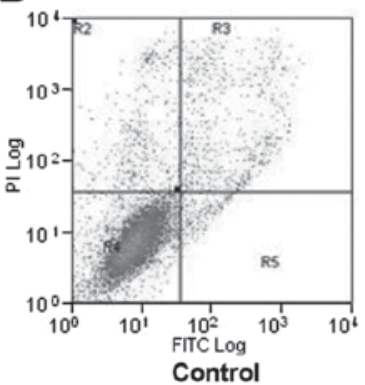

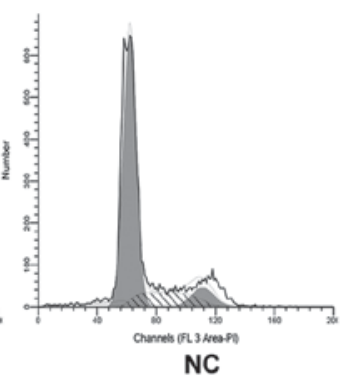

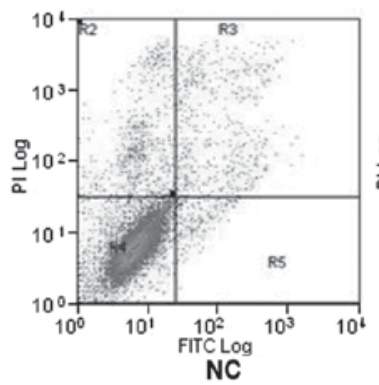

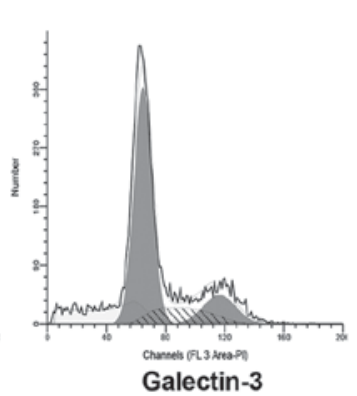

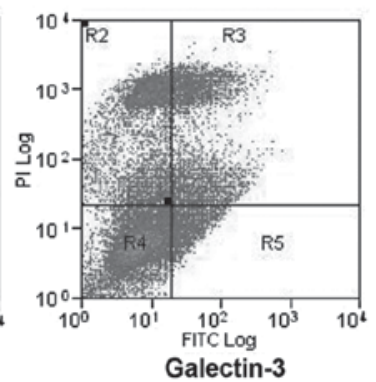

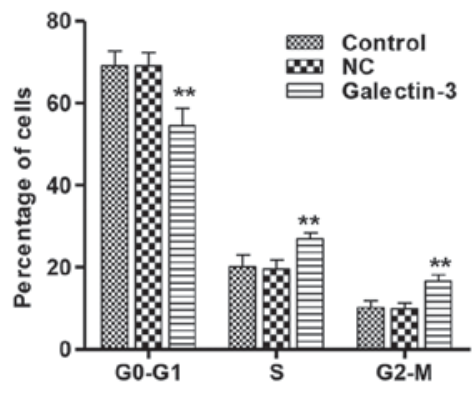

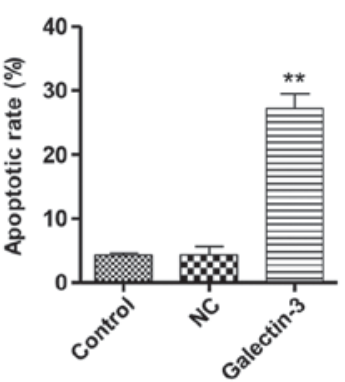

Figure 2. Effects of galectin-3 overexpression on cell cycle progression and apoptosis of cardiomyocytes. (A) Cell cycle analysis of cardiomyocytes with galectin-3 overexpression was performed by PI staining and flow cytometry. (B) Apoptosis of cardiomyocytes with galectin-3 overexpression was measured by Annexin V-FITC/PI staining and flow cytometry. Data are presented as the mean \pm standard deviation $(\mathrm{n}=3)$. ${ }^{* *} \mathrm{P}<0.01$ vs. NC group. PI, propidium iodide; FITC, fluorescein isothiocyanate; NC, negative control.

A

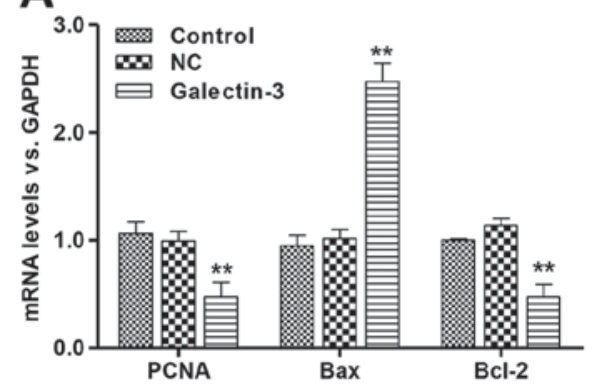

B

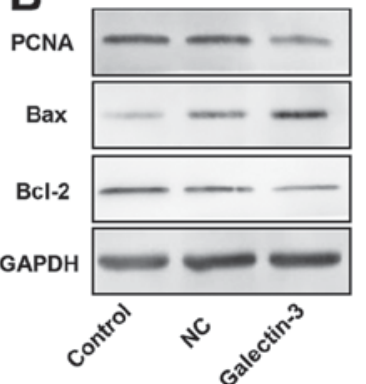

C

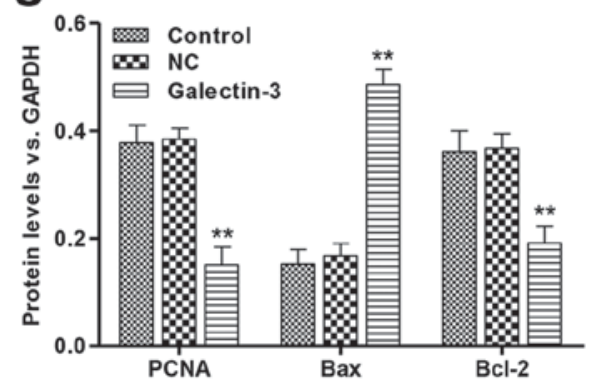

Figure 3. Effects of galectin-3 overexpression on PCNA, Bcl-2 and Bax expression in cardiomyocytes. (A) Reverse transcription-quantitative polymerase chain reaction of PCNA, Bcl-2 and Bax expression profiles in the three treatment groups. (B) Western blot analysis and (C) semi-quantification of PCNA, Bcl-2 and Bax expression profiles in the three treatment groups. Data are presented as the mean \pm standard deviation $(\mathrm{n}=3)$. ${ }^{* *} \mathrm{P}<0.01 \mathrm{vs}$. NC group. PCNA, proliferating cell nuclear antigen; Bcl-2, B-cell lymphoma 2; Bax, Bcl-2-associated X protein; NC, negative control.

results demonstrate that galectin-3 overexpression may decrease PCNA expression and decrease the ratio of Bcl-2/Bax, which may contribute to the observed increase in cell apoptosis.

Therapeutic silencing of galectin-3 improves cardiomyocyte survival during heart failure. The potential therapeutic impact of galectin-3 inhibition was investigated in vivo. Dahl salt-sensitive rats were fed a $\mathrm{HS}$ diet $(8.0 \% \mathrm{NaCl})$, which causes the rats to progress to a model of heart failure. After 1 week on the HS diet, rats were intravenously injected with galectin-3 shRNA or shNC, stably expressed in the pLKO.1 lentiviral vector. Knockdown of galectin-3 significantly decreased the expression levels of galectin-3 in the cardiac tissue of rats with heart failure (Fig. 4A-C). After 4 weeks on the HS diet, the control and shNC rats started to exhibit signs of discomfort and were sacrificed; however, intravenous injection of galectin-3 shRNA significantly increased the survival rate (Fig. 4D). As a surrogate indicator of overall health, body weight was regularly monitored for the duration of the study (1). All the rats gained weight together until day 14 of the HS diet, whereas rats in the control and shNC groups after day 14 of HS diet exhibited significantly reduced weight gain, compared with the rats injected with galectin-3 shRNA (Fig. 4E).

Effect of galectin-3 silencing on PCNA, Bcl-2 and Bax expression in Dahl hypertensive rats. To investigate the regulation of proliferation- and apoptosis-associated genes, PCNA, Bcl-2 and Bax mRNA and protein levels were assessed in the cardiac tissue of Dahl hypertensive rats. PCNA and Bcl-2 mRNA levels were significantly increased in HS-induced rats injected with galectin-3 shRNA (Fig. 5A). Furthermore, treatment with galectin-3 shRNA significantly decreased the Bax mRNA expression level in HS-induced rats. The altered regulation 

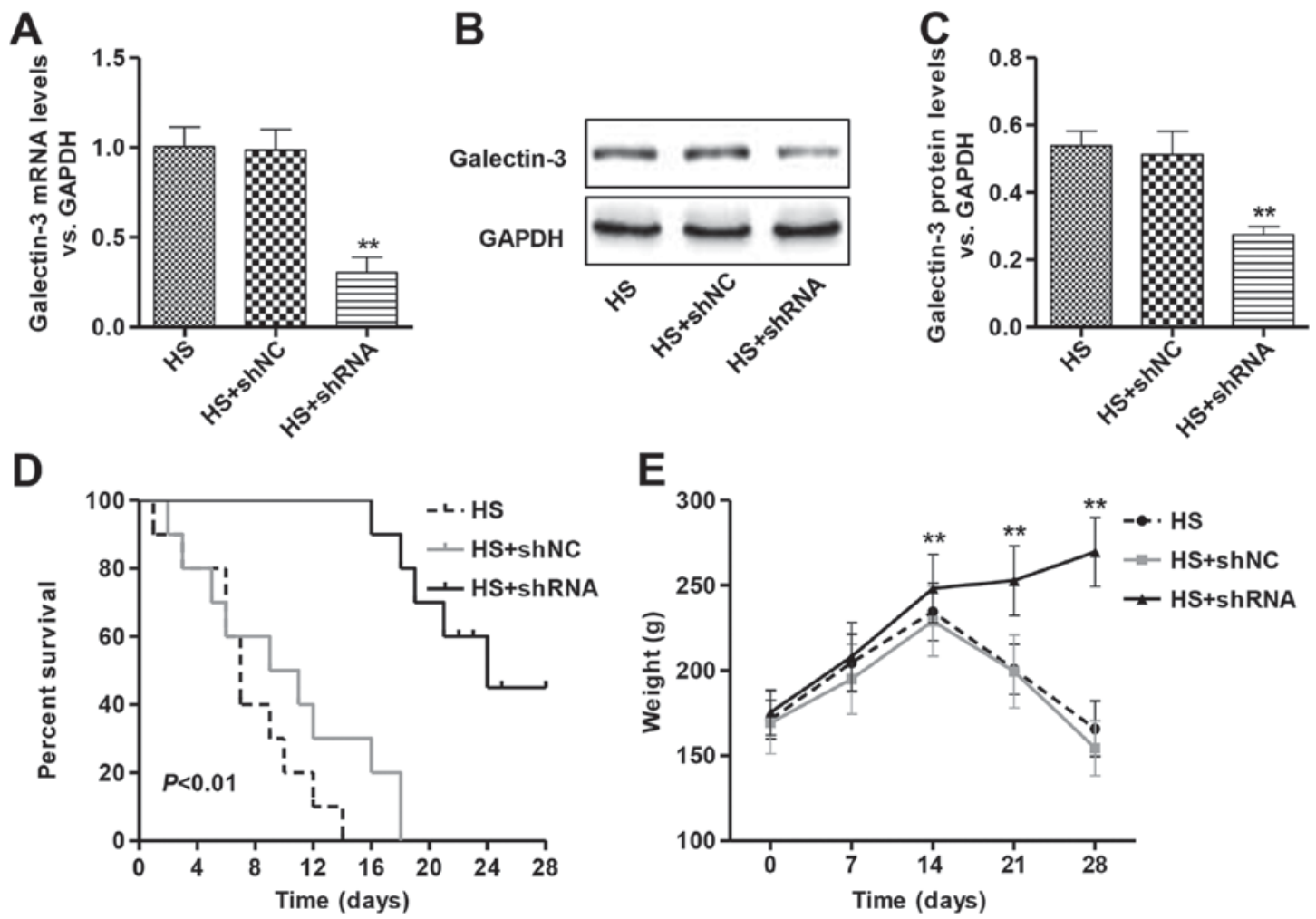

Figure 4. Therapeutic effect of galectin-3 knockdown on Dahl hypertensive rats. (A) Reverse transcription-quantitative polymerase chain reaction of galectin-3 expression profiles in the cardiac tissue of hypertensive rats. (B) Western blot analysis and (C) semi-quantification of galectin-3 expression profiles in the cardiac tissue of hypertensive rats. (D) Kaplan-Meier survival curves of the Dahl hypertensive rat model, demonstrating a pronounced decrease in survival in response to an $8 \%$ HS diet. Survival is significantly improved withgalectin-3 inhibition treatment. (E) Body weight analysis of Dahl hypertensive rats on the $8 \%$ HS diet reveals significant reductions in weight after 14 days. This was not observed in rats that receivedgalectin-3 inhibition treatment. Data are presented as the mean \pm standard deviation ( $\mathrm{n}=6 /$ group). ${ }^{* *} \mathrm{P}<0.01 \mathrm{vs.} \mathrm{HS}+$ shNC group. HS, high-salt; shRNA, short hairpin RNA; shNC, negative control shRNA.
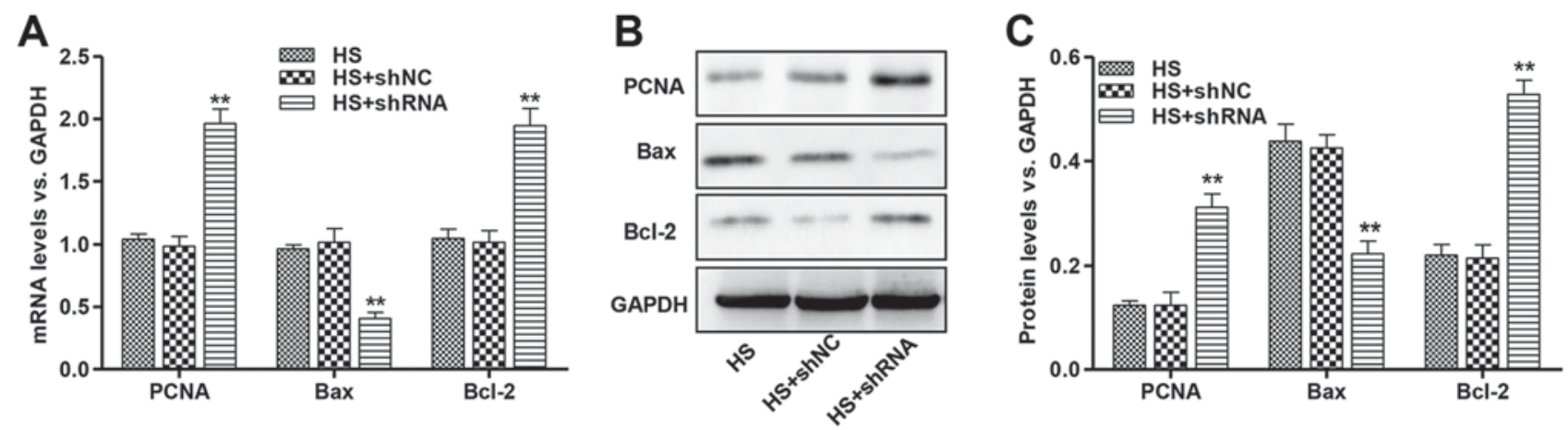

Figure 5. Effect of galectin-3 knockdown on PCNA, Bcl-2 and Bax expression in Dahl hypertensive rats. (A) Reverse transcription-quantitative polymerase chain reaction analysis of PCNA, Bcl-2 and Bax expression profiles in the cardiac tissue of hypertensive rats after 4 weeks on the HS diet. (B) Western blot analysis and (C) semi-quantification of PCNA, Bcl-2 and Bax expression profiles in the cardiac tissue of hypertensive rats after 4 weeks on the HS diet. Data are presented as the mean \pm standard deviation $(\mathrm{n}=6)$. ${ }^{* *} \mathrm{P}<0.01 \mathrm{vs}$. HS+shNC groups. PCNA, proliferating cell nuclear antigen; Bcl-2, B-cell lymphoma 2; Bax, Bcl-2-associated X protein; HS, high-salt; shRNA, short hairpin RNA; shNC, negative control shRNA.

of these proteins was confirmed by western blot analysis (Fig. 5B and C). These results demonstrate that galectin-3 knockdown may increase PCNA and the Bcl-2/Bax ratio, which may lead to an increase in cardiomyocyte survival.

\section{Discussion}

Galectin-3 is expressed in various tissues and cell types and is involved in several biological processes, including cell proliferation, cell cycle, apoptosis and angiogenesis (22).
An increased concentration of galectin-3 has been identified in patients with HF and this protein may be promising for high-risk patient identification (23). The present study demonstrated that higher levels of galectin-3, a marker of cardiac fibrosis (24), are associated with the development and progression of HF. To the best of our knowledge, this is the first study to report the association of galectin-3 with cardiomyocyte proliferation and apoptosis in vitro, and with survival in vivo. The present study has also indicated that the HF-promoting galectin-3 mechanisms may be associated 
with decreased expression of PCNA and Bcl-2, and increased expression of Bax.

Experimental evidence has suggested that galectin-3 is the most predominantly overexpressed gene in transgenic Ren-2 rats that progress to HF (7). The present study revealed that overexpression of galectin-3 in cardiomyocytes resulted in suppression of cell proliferation in a time-dependent manner, accompanied by apoptosis and cell cycle arrest at $S$ and $\mathrm{G}_{2}-\mathrm{M}$ phases. These data suggest that galectin- 3 overexpression may contribute to cardiac dysfunction by inducing cardiomyocyte cell cycle arrest and apoptosis. In agreement with these findings, infusion of galectin-3 into the pericardial space leads to cardiac dysfunction in rats, a process that appears to be mediated via the transforming growth factor- $\beta /$ SMAD family member 3 signaling pathway (8). However, several studies have indicated that galectin-3 overexpression regulates the cell cycle and apoptosis via alterations in the expression levels of cell cycle regulators, including cyclin D1. Notably, the growth-promoting activity of galectin-3 is predominantly dependent on cyclin D1 promoter activity $(25,26)$. The expression of PCNA and Bcl-2 were significantly decreased in galectin-3 overexpressing cardiomyocytes, whereas the Bax expression was elevated, suggesting that galectin-3 may arrest the cell cycle and induce apoptosis via regulation of the PCNA and Bcl-2/Bax pathways.

Experimental evidence for the involvement of galectin-3 in HF development came from studies that galectin-3 inhibition in mice resulted in a marked reduction of cardiac fibrosis, and thus, may be beneficial in the prevention of $\operatorname{HF}(8,27)$. Similarly, in the present study, the therapeutic effects of galectin-3 inhibition in the Dahl hypertensive rats provided evidence that intravenous tail vein injections of galectin-3-shRNA is sufficient to deliver galectin-3-shRNA effectively to the heart in vivo, and that galectin-3 inhibition results in the increased survival and weight gain of Dahl hypertensive rats, compared with rats without galectin-3 inhibition. Cell cycle and apoptosis-associated proteins, including PCNA, Bcl-2 and Bax, were also detected in Dahl hypertensive rats. The results indicated that galectin-3 inhibition significantly increased the expression of PCNA and Bcl-2, and decreased the expression of Bax, compared with Dahl hypertensive rats without galectin-3 inhibition. These results suggested that PCNA and the Bcl-2/Bax pathway were also involved in the galectin-3 silencing-dependent promotion of the survival and weight gain of Dahl hypertensive rats.

Subsequent pharmacokinetic and efficacy studies in larger mammals are required to establish whether inhibition of galectin-3 is able to establish a comparable therapeutic effect in larger animals. In addition, therapeutic galectin-3 inhibition would likely involve combination with the current standard treatments in used for patients with HF; thus, it will be important to assess whether galectin-3 inhibition, in conjunction with current treatments, adds to the beneficial effects of these drugs. Taken together, this study demonstrates that overexpression of galectin-3 in cardiomyocytes inhibits cell proliferation, arrests the cell cycle and induces apoptosis. Galectin-3 inhibition in Dahl hypertensive rats increased survival and further validates galectin-3 as a potential target for cardiac disease therapy.

\section{References}

1. Montgomery RL, Hullinger TG, Semus HM, Dickinson BA, Seto AG, Lynch JM, Stack C, Latimer PA, Olson EN and van Rooij E: Therapeutic inhibition of miR-208a improves cardiac function and survival during heart failure. Circulation 124: 1537-1547, 2011.

2. Mozaffarian D, Benjamin EJ, Go AS, Arnett DK, Blaha MJ, Cushman M, de Ferranti S, Després JP, Fullerton HJ, Howard VJ, et al: Heart disease and stroke statistics-2015 update: A report from the American heart association. Circulation 131: e29-e322, 2015.

3. Guha K and McDonagh T: Heart failure epidemiology: European perspective. Curr Cardiol Rev 9: 123-127, 2013.

4. Hu SS, Kong LZ, Gao RL, Zhu ML, Wang W, Wang YJ, Wu ZS, Chen WW and Liu MB; Editorial Board: Outline of the report on cardiovascular disease in China, 2010. Biomed Environ Sci 25: 251-256, 2012.

5. Bui AL, Horwich TB and Fonarow GC: Epidemiology and risk profile of heart failure. Nat Rev Cardiol 8: 30-41, 2011.

6. Spinelli L, Stabile E, Giugliano G, Morisco C, Giudice CA, Imbriaco M, Santoro M, Esposito G and Trimarco B: Intramyocardial dissecting hematoma in anterior wall ST elevation myocardial infarction: Impact on left ventricular remodeling and prognosis. Int J Cardiovasc Imaging: Aug 1, 2017 (Epub ahead of print).

7. Sharma UC, Pokharel S, van Brakel TJ, van Berlo JH, Cleutjens JP, Schroen B, André S, Crijns HJ, Gabius HJ, Maessen J and Pinto YM: Galectin-3 marks activated macrophages in failure-prone hypertrophied hearts and contributes to cardiac dysfunction. Circulation 110: 3121-3128, 2004.

8. Liu YH, D'Ambrosio M, Liao TD, Peng H, Rhaleb NE, Sharma U, André S, Gabius HJ and Carretero OA: N-acetyl-seryl-aspart yl-lysyl-proline prevents cardiac remodeling and dysfunction induced by galectin-3, a mammalian adhesion/growth-regulatory lectin. Am J Physiol Heart Circ Physiol 296: H404-H412, 2009.

9. de Boer RA, Yu L and van Veldhuisen DJ: Galectin-3 in cardiac remodeling and heart failure. Curr Heart Fail Rep 7: 1-8, 2010.

10. Henderson NC, Mackinnon AC, Farnworth SL, Poirier F, Russo FP, Iredale JP, Haslett C, Simpson KJ and Sethi T: Galectin-3 regulates myofibroblast activation and hepatic fibrosis. Proc Natl Acad Sci USA 103: 5060-5065, 2006.

11. Henderson NC, Mackinnon AC, Farnworth SL, Kipari T, Haslett C, Iredale JP, Liu FT, Hughes J and Sethi T: Galectin-3 expression and secretion links macrophages to the promotion of renal fibrosis. Am J Pathol 172: 288-298, 2008.

12. van den Borne SW, Diez J, Blankesteijn WM, Verjans J, Hofstra L and Narula J: Myocardial remodeling after infarction: The role of myofibroblasts. Nat Rev Cardiol 7: 30-37, 2010.

13. de Boer RA, Voors AA, Muntendam P, van Gilst WH and van Veldhuisen DJ: Galectin-3: A novel mediator of heart failure development and progression. Eur J Heart Fail 11: 811-817, 2009.

14. Anand IS, Rector TS, Kuskowski M, Adourian A, Muntendam P and Cohn JN: Baseline and serial measurements of galectin-3 in patients with heart failure: Relationship to prognosis and effect of treatment with valsartan in the Val-HeFT. Eur J Heart Fail 15: 511-518, 2013.

15. Wei F, Wang TZ, Zhang J, Yuan ZY, Tian HY, Ni YJ, Zhuo XZ, Han K, Liu Y, Lu Q, et al: Mesenchymal stem cells neither fully acquire the electrophysiological properties of mature cardiomyocytes nor promote ventricular arrhythmias in infarcted rats. Basic Res Cardiol 107: 274, 2012.

16. Rodenbaugh DW, Wang W, Davis J, Edwards T, Potter JD and Metzger JM: Parvalbumin isoforms differentially accelerate cardiac myocyte relaxation kinetics in an animal model of diastolic dysfunction. Am J Physiol Heart Circ Physiol 293: H1705-H1713, 2007.

17. National Institutes of Health: Guide for the Care and Use of Laboratory Animals. NIH publication no. 85_/23. National Institutes of Health, Rockville, MD, 1996.

18. Livak KJ and Schmittgen TD: Analysis of relative gene expression data using real-time quantitative PCR and the 2(-Delta Delta C(T)) method. Methods 25: 402-408, 2001.

19. Wang XH, Zhuo XZ, Ni YJ, Gong M, Wang TZ, Lu Q and Ma AQ: Improvement of cardiac function and reversal of gap junction remodeling by neuregulin- $1 \beta$ in volume-overloaded rats with heart failure. J Geriatr Cardiol 9: 172-179, 2012. 
20. Niwa M, Miwa Y, Kuzuya T, Iwasaki K, Haneda M, Ueki T, Katayama A, Hiramitsu T, Goto N, Nagasaka T, et al: Stimulation index for PCNA mRNA in peripheral blood as immune function monitoring after renal transplantation. Transplantation 87: $1411-1414,2009$.

21. Hetz C: BCL-2 protein family. Essential regulators of cell death. Preface. Adv Exp Med Biol 687: vii-viii, 2010.

22. Hrynchyshyn N, Jourdain P, Desnos M, Diebold B and Funck F: Galectin-3: A new biomarker for the diagnosis, analysis and prognosis of acute and chronic heart failure. Arch Cardiovasc Dis 106: 541-546, 2013.

23. Gaggin HK and Januzzi JL Jr: Biomarkers and diagnostics in heart failure. Biochim Biophys Acta 1832: 2442-2450, 2013.

24. Ho JE, Liu C, Lyass A, Courchesne P, Pencina MJ, Vasan RS, Larson MG and Levy D: Galectin-3, a marker of cardiac fibrosis, predicts incident heart failure in the community. J Am Coll Cardiol 60: 1249-1256, 2012.
25. Yoshii T, Fukumori T, Honjo Y, Inohara H, Kim HR and Raz A: Galectin-3 phosphorylation is required for its anti-apoptotic function and cell cycle arrest. J Biol Chem 277: 6852-6857, 2002.

26. Lin HM, Pestell RG, Raz A and Kim HR: Galectin-3 enhances cyclin D(1) promoter activity through SP1 and a cAMP-responsive element in human breast epithelial cells. Oncogene 21: 8001-8010, 2002.

27. Yu L, Ruifrok WP, Meissner M, Bos EM, van Goor H, Sanjabi B, van der Harst P, Pitt B, Goldstein IJ, Koerts JA, et al: Genetic and pharmacological inhibition of galectin-3 prevents cardiac remodeling by interfering with myocardial fibrogenesis. Circ Heart Fail 6: 107-117, 2013. 